\title{
Screening of risk from patient manual handling with MAPO method
}

\author{
Natale Battevi* and Olga Menoni* \\ "IRCCS Ca' Granda Ospedale Policlinico Foundation, Milan (Italy)- Department of Occupational Health" \\ Clinica del Lavoro L. Devoto" University of Milan - Via S. Barnaba 8 - 20122 Milano
}

\begin{abstract}
International standards highlight the steps required by risk assessment and involving first hazard identification, then risk evaluation and finally, if necessary, risk assessment. To check approach appropriateness to "risk evaluation" from manual patient handling through MAPO, a cross study was carried out in view of checking relationship between this new risk assessment model and occurrence of acute low back pain. After proper training the MAPO screening method was assessed in 31 wards, 411 exposed subjects of geriatric hospitals. At the same time health data were collected on occurrence of low back pain episodes during the last year both in the exposed subjects' group and the external reference group ( $\mathrm{n}^{\circ} 237$ ). Risk and clinical assessment data were tutored and checked by EPM research unit. The logistic analysis was used as a method to evaluate the relationship between risk index and acute low back pain. Investigating relationship between acute low back pain episodes and levels of MAPO screening index, carried out only with the people exposed who claimed to work for at least 30 hours per week $(\mathrm{n}=178)$, showed definitely positive trends. The study results indicate that MAPO screening may represent a useful tool to estimate the risk from manual handling patients.
\end{abstract}

Keywords: Lifting patients; low back pain; risk assessment; nurses

\section{Introduction}

Risk assessment is the basic knowledge to identify the actions likely to improve working conditions. Not only, its unceasing updating allows periodical check of undertaken actions. These assets however are often in contrast with the application of risk assessment methodologies needing long analysis times. International standards $(12,21,22)$ already tackled this issue and suggest a process that starting form identification of hazards propose first risk estimation and if necessary actual risk evaluation.

For patient manual handling risk, a hazard can be easily identified by the presence of patients who, because of their health (motorial or cognitive) conditions need a help for mobilization.

Methods for risk estimation are scarce if not at all absent while there are several methodologies for risk assessment $(20,23-25,37)$ including the MAPO method proposed ever since 1999 (5, 32, 36) by EPM (Ergonomics of Posture and Movement) Research Unit widely applied not only in Italy but also in Spain (1).

This method is characterized by analytical quickness, that generally needs a limited time for assessing a hospital ward (approx 1 hour), as well as by its positive correlation with acute lumbar injury $(4,5)$. Hence it turns out to be an actual risk assessment method for patient handling since for increasing levels of index, the outcome was an increase in acute lumbar injury prevalence.

It is worth recalling that national and international literature $(2,3,6-8,10,11,17-19,26-30,33,34,38$ 41) has long highlighted that acute and chronic lumbar injury is one of the most relevant problems among health care workers not only for its negative impact on workers' health but also because of its economic relevance.

*Corresponding author.E-mail: epmnatale@tiscali.it 
Another issue to be considered is the population demographic trend specially in western countries witnessing its progressive aging and consequently an increased number of people needing health care. The increased number of beds in elderly long-term patient rest homes is a phenomenon not strictly related to Italy but to whole Europe.

Among the organizations dealing in Italy with non cooperative elderly people assistance UNEBA (National Union of social security institutions and initiatives) has a top position: suffice to think that in the Veneto Region alone it takes care of 9000 people with a staff of 5600. UNEBA section in Veneto region promoted, jointly with EPM Research Unit, a screening investigation for MAPO application to its structures. In particular the OIC institute (Immaculate Conception Charity) sponsored a study to assess risk from patient handling in its elderly rest homes (RSA) as well as from acute lumbar injury whose results between 2008 and 2009 are reported.

\section{Methods}

To ensure application of uniform research methodologies in the units participating in this study, EPM Research Unit in 2008 delivered a $14 \mathrm{~h}$ theoretical-practical training in risk assessment by screening MAPO methodology (9) mainly addressed to technical staff of the health care structures involved. Instead, the health staff made up of occupational doctors was trained in musculoskeletal disorders by a 7 hour course.

In 2008-2009, 31 hospital wards were investigated belonging to 10 geriatric rest homes in the Veneto Region. Gathered health data concerned exposed subjects $(n=411)$ and a reference sample $(n=237)$ always in 2008-2009. The reference sample included clerical staff using VDT for at least 20 hours a week in a range of situations (municipality, health structures and court) without being exposed to load handling and living in the same territory as RSA.

Data processing excluded subjects with ward seniority less than six months and wards with no data on acute lumbar injury in at least $70 \%$ of exposed subjects.

For descriptive analysis of data, referred to the whole observed sample and the external reference sample, the SPSS statistical analysis programme was used. Exposure versus injury association was investigated by the unconditioned logistic analysis technique using the STATA 6.0 statistical analysis programme. For each subject included into the study, the response variable (acute lumbar injury) was considered as binary: presence of injury (at least one episode of acute low back pain in the last year) and absence of injury (no episode). This analysis was concerned only with the exposed subjects working over three shifts in $24 \mathrm{~h}$ for at least 30 hours per week $(\mathrm{n}=178)$.

Then the Odds ratios, both rough and adjusted by gender and age class, were calculated for increasing exposure levels using the external reference sample.

\subsection{Risk assessment}

Risk was assessed by MAPO method $(5,32)$ summarizing exposure level by the following mathematical expression:

$$
\mathrm{MAPO}=(\mathrm{NC} / \mathrm{Op} \times \mathrm{LF}+\mathrm{PC} / \mathrm{Op} \times \mathrm{AF}) \times \mathrm{WF} \times \mathrm{EF} \times \mathrm{TF}
$$

where NC/Op is the relationship between NonCooperative Patients and Operators present in the three shifts, and PC/Op is the ratio between Partially Cooperative Patients and the Operators present in the three shifts; $\mathbf{L F}$ is the lifting factor; $\mathbf{A F}$ is the minor aids factor; WF is the wheelchair factor; EF is the environment factor and $\mathbf{T F}$ is the training factor.

Factors NC, PC, Op, LF, AF and TF are collected during an interview with ward head or anyhow with the senior ward operator, WF and EF can be assessed only via a ward inspection.

In the present proposal, screening analysis by MAPO included only the interview making the other factors (WF and EF) equal to one and hence making them no influent for MAPO index calculation. Thus the estimation of exposure level to $\mathrm{PMH}$ risk is even quicker.

Some clarifications were brought about as compared with MAPO method presented in 1999 and $2003(16,32)$ to achieve assessment less sensitive to interviewer's education and training and already anticipated in the discussion on the paper published in Ergonomics in 2006 (5).

First of all more and more frequently operators work with more and more flexible work shifts (vertical/horizontal part time with major weekly hour differences and sometimes concentrated on the hours of more frequent patient handling) specially in rest homes but also in acute hospitals: this might involve an overestimation of parameter Op.

This is the reason why in the data recording sheet a special section was added to calculate the contribution by each operator as his/her shift time fraction. An example, referred to 7 hour work shifts, is reported in table 1 . 
Table 1

Calculation example of value to be attributed to Operators (OP) working part-time in the shift

\begin{tabular}{cccc}
\hline $\begin{array}{c}\text { No of operators } \\
\text { working part time }\end{array}$ & $\begin{array}{c}\text { Working time in shift } \\
\text { (from 00:00 to 00:00) }\end{array}$ & $\begin{array}{c}\text { Unit } \\
\text { fraction }\end{array}$ & $\begin{array}{c}\text { Unit fraction per number } \\
\text { of present operators }\end{array}$ \\
\hline $\mathbf{1}$ & From 8.00 to 12.00 & $\mathbf{4 / 7}$ & $\mathbf{0 , 5 7}$ \\
\hline $\mathbf{1}$ & From 9.00 to 11.00 & $\mathbf{2 / 7}$ & $\mathbf{0 , 2 8}$ \\
\hline
\end{tabular}

Also "Lifting device factor" (LF) was analytically defined in respect to its original formulation: numerical sufficiency and adequacy to ward needs. First as regards its definition since this parameter must not consider lifting devices as unique equipment for $\mathrm{NC}$ patient handling but other equipment have to be considered as well. For example ergonomic beds preventing patient sliding downwards and hence decreasing the need for displacements towards the pillow.

As regards numerical sufficiency, beside keeping a ratio of 1 patient lifting device every $8 \mathrm{NC}$ patients (or height adjustable stretcher with highly slippery cloth/table), it is considered to be present also when all ward beds have three joints and are height adjustable. The other element allowing correct attribution of a value to "Factor lifting device" is adequacy to ward needs. This concept was developed in terms of qualitative attributes to be considered as an altogether by the interviewer: adequacy to patients currently present in the ward, aid maintenance and finally space characteristics of use.

To overcome interviewer's subjectivity, the data recording sheet included also a section reporting the description of handling currently carried out in ward, subdivided into operations requiring full lifting of patient (ST) and operations requiring movement or partial lifting of patient (SP). In their turn the latter are subdivided into manual handling operations ( no equipment) and operations with aids (with equipment). To facilitate recording, handling operations were detailed for specific task and shift. By "current" operations, we mean daily handling to most non cooperative patients (31).

Thus it is possible to quantify with sufficient approximation the percentage of total and partial lifting with aids. Once this percentage has been obtained, the "adequacy" requirement could be attributed only when at least $90 \%$ of Total Lifting (ST) is handled with aid/equipment. This also allows to define more objectively the concept of adequacy also for "Minor aids factor". In this case handling requiring a Partial Lifting (SP) is considered.

Another issue is the value attribution procedure to "Education and training factor". The criteria are aimed at better meeting the increasingly apparent turnover of health care workers noticeable in Italy and other European countries. In addition to the characteristics identified in the previous methodological proposals (contents and duration) of education and training, the time elapsed between education course and risk assessment was considered as well as the possible education effectiveness check. The new proposal includes Education and Training Factor values as reported in table 2 .

Table 2

Criteria for value attribution to Training Factor (TF)

\begin{tabular}{|l|c|}
\hline \multicolumn{1}{|c|}{ Observed characteristics } & Value of TF \\
\hline Training via appropriate course, delivered not over two years before risk assessment and to $75 \%$ of ward operators & $\mathbf{0 , 7 5}$ \\
\hline If delivered over 2 years before risk assessment to $75 \%$ of ward operators and if effectiveness has been checked & $\mathbf{0 , 7 5}$ \\
\hline $\begin{array}{l}\text { Training via appropriate course delivered not over two years before risk assessment and to a percentage of operators } \\
\text { from 50 to 75 }\end{array}$ & $\mathbf{1}$ \\
\hline If only information material to 90\% of ward operators and effectiveness have been checked & $\mathbf{1}$ \\
\hline Not delivered or not meeting the above mentioned requirements & $\mathbf{2}$ \\
\hline
\end{tabular}

The last issue considered in this study is retrieval of information regarding number of working week hours per involved subject and if worked over three shifts. This is a key element since once a ward risk level has been calculated by MAPO screening method, the latter is ascribed to the homogenous 
group of operators in charge with patient handling in that ward at equal working hours.

\subsection{Injury assessment}

The injury variable used in the study deals with the episodes of acute low back pain occurred in the last 12 months (14). This variable is defined as "presence of progressively severe low back pain with or without irradiation forcing the patient in bed for two days or one if taking anti-inflammatory non corticosteroid and/or relaxants drugs". This kind of episodes shall also produce a sick leave to better differentiate the chronic low back pain from acute low back pain.

This choice was due to the well known direct ratio between lumbar biomechanical overload and stimulation of low back pain (29).

Data collection for exposed sample as well as for external reference group was entrusted to occupational physicians after a period of training and checked by EPM research unit supervisors.

\section{Results}

\subsection{Exposure levels of investigated wards}

In investigated workplaces all operators belong to the professional profile of Health Care Workers (OSS): this qualification corresponds to a 600 hour educational process. Instead, no professional nurses are present. All wards $(n=31)$ with number of beds between 15 and 51 are characterized by the presence of $\mathrm{NC}$ and $\mathrm{PC}$ patients.
MAPO index level by screening was on average equal to 4.3 with 2.9 standard deviation and range between 1.2 and 13.8 value.

Only two wards $(6.5 \%)$ showed a negligible risk level ( 0.1 to 1.50 of MAPO index) whereas $70-9 \%$ evidenced an index within the range of average risk $(1.51$ to 5,00$)$ and the remaining wards $(22.6 \%)$ were classified as having a high PMH risk (MAPO index exceeding 5).

Out of the 411 exposed subjects, 306 work over the three shifts while the others have quite different working schedules: by day, vertical or horizontal part time, interrupted working time (e.g. $9.00-11.00$ and 15.00-17.00).

\subsection{Sample characteristics of investigated subjects}

On the whole, from the health standpoint, 648 subjects were assessed, out of whom 411 exposed and 237 non exposed subjects, $17.4 \%$ males and $82.6 \%$ females. The average age was 45.4 years, a rather high one, while age class distribution can be seen in table 3.

Classes of advanced age are well represented. Analysis of different parameters between exposed and non-exposed subjects is quite interesting: for example in the group of exposed subjects average age is 47.3 years while it is 43.3 for non exposed subjects. Gender difference is more appreciable: in particular, males are $36.7 \%$ within non-exposed subjects while they are only $6.3 \%$ within exposed subjects. This difference is not so marked in the exposed subjects that will be considered for studying association between screening MAPO index and acute low back pain. Actually in this subsample, males are $10.1 \%$ versus $\quad 89.9 \%$ females.

Table 3

Comparison of age class and sex distribution between exposed and non-exposed subjects

\begin{tabular}{ccccccccc}
\hline & \multicolumn{3}{c}{ Exposed subjects } & \multicolumn{3}{c}{ Non exposed subjects } \\
\hline & \multicolumn{2}{c}{ males } & \multicolumn{2}{c}{ females } & \multicolumn{2}{c}{ males } & \multicolumn{2}{c}{ females } \\
\hline Age classes (years) & $\mathrm{N}^{\circ}$ & $\%$ & $\mathrm{~N}^{\circ}$ & $\%$ & $\mathrm{~N}^{\circ}$ & $\%$ & $\mathrm{~N}^{\circ}$ & $\%$ \\
\hline up to 25 & $\mathbf{1}$ & 3,8 & $\mathbf{1 6}$ & 4,2 & $\mathbf{1 0}$ & 11,5 & $\mathbf{1 6}$ & 10,7 \\
\hline 26 to 35 & $\mathbf{6}$ & 23,1 & $\mathbf{6 7}$ & 17,4 & $\mathbf{2 0}$ & 23,0 & $\mathbf{2 6}$ & 17,3 \\
\hline 36 to 45 & $\mathbf{1 1}$ & 42,3 & $\mathbf{1 4 5}$ & 37,7 & $\mathbf{1 7}$ & 19,5 & $\mathbf{3 8}$ & 25,3 \\
\hline 46 to 55 & $\mathbf{7}$ & 26,9 & $\mathbf{1 4 4}$ & 37,4 & $\mathbf{2 9}$ & 33,3 & $\mathbf{4 9}$ & 32,7 \\
\hline over 55 & $\mathbf{1}$ & 3,8 & $\mathbf{1 3}$ & 3,4 & $\mathbf{1 1}$ & 12,6 & $\mathbf{2 1}$ & 14,0 \\
\hline Total & $\mathbf{2 6}$ & 6,3 & $\mathbf{3 8 5}$ & 93,7 & $\mathbf{8 7}$ & 36,7 & $\mathbf{1 5 0}$ & 63,3 \\
\hline
\end{tabular}


Differences between the two groups are however more interesting both in terms of subjects reporting at least one episode of acute low back pain in the last year ( 9.0 vs 4.6$)$ and in terms of lumbar disc herniated prevalence (6.8 vs 3.0$)$.

It is noteworthy that lumbar degenerative disease was considered only when the subject exhibited the referral of instrumental examination certifying its presence.

\subsection{Study of ratio of MAPO index (screening) and acute lumbar injury occurred in the last 12 months}

Since in the analyzed sample, the number of subjects exposed to a MAPO index level less than or equal to 1.5 (negligible exposure) was very low, the comparison for MAPO index classes was made with the sample of subjects identified as "external reference" and where injury variable was gathered in the same period and same geographic areas as resthomes. In the reference sample the prevalence of subjects with at least one episode of acute low back pain in the last 12 months is around a $4.6 \%$.

The variety of adopted criteria limited the number of exposed subjects considered to be worth for the sake of this study. Hence analysis was carried out on 306 subjects and 20 wards. Therefore MAPO index values considered for this analysis are: zero exposure level, medium level (MAPO between 1.51 and 5.0) and high level (MAPO higher than 5).

The first descriptive analysis highlighted that not all the subjects working on shifts have actually a 36 hour working time schedule (as per contract) but may have week working times between 18 and 38 hours. A rough analysis of acute low back pain prevalence in the last 12 months is reported in table 4 showing groups characterized by a different exposure week duration.

Albeit the group of exposed subjects working over three shifts for at least 24 hours includes also subjects working for at least 30 hours, this description highlights the increase of acute low back pain prevalence occurred in the last year, with increasing exposure duration.

Data were then analyzed with logistic regression considering the exposed subjects working over three shifts for at least 30 hours per week (table 5).

Analysis of results clearly evidences a positive trend (35) of prevalence of acute low back pain episodes as compared with exposure level: in particular OR for subjects exposed to MAPO level between 1.51 and 5 is double (OR 2.22) as compared with the sample of non exposed subjects. Instead, in MAPO index class exceeding 5, OR becomes four times higher (OR 3.77) and the result does not practically change when introducing possible confounding factors such as gender and age classes.

Table 4

Analysis of low back pain prevalence by MAPO screening exposure index level and by number of worked hours

\begin{tabular}{|c|c|c|c|c|}
\hline & \multicolumn{2}{|c|}{$\begin{array}{l}\text { Acute low back pain in wards with } \\
\text { MAPO index between } 1,51 \text { and } 5\end{array}$} & \multicolumn{2}{|c|}{$\begin{array}{c}\text { Acute low back pain in } \\
\text { wards with MAPO index }>5\end{array}$} \\
\hline & $\mathrm{N}^{\circ}$ & $\%$ & $\mathrm{~N}^{\circ}$ & $\%$ \\
\hline All subjects working over three shifts $(\mathrm{N}=306)$ & 17 & 6,9 & 8 & 13,1 \\
\hline $\begin{array}{l}\text { Subjects working over three shifts for at least } 24 \text { hours a week } \\
(\mathrm{N}=249)\end{array}$ & 15 & 8,2 & 8 & 14,3 \\
\hline $\begin{array}{l}\text { Subjects working over three shifts for at least } 30 \text { hours a week } \\
(\mathrm{N}=178)\end{array}$ & 12 & 9,7 & 8 & 14,8 \\
\hline
\end{tabular}


Table 5

Results of association study between MAPO screening exposure indices and acute low back pain in the last yearsubjects working over three shifts for at least 30 hour a week.

\begin{tabular}{|c|c|c|c|c|c|c|}
\hline & \multicolumn{2}{|c|}{$\begin{array}{c}\text { Acute low back pain last } \\
\text { year }\end{array}$} & \multirow[t]{2}{*}{ Odds ratio } & \multirow[t]{2}{*}{ IC $(95 \%)$} & \multirow[t]{2}{*}{ Correct Odds ratio } & \multirow[t]{2}{*}{ Correct IC (95\%) } \\
\hline & Neg & Pos & & & & \\
\hline $\begin{array}{c}\text { MAPO Index } \\
0 \\
1.51-5 \\
5.01-10 \\
\text { P value for trend } \\
\end{array}$ & $\begin{array}{c}226 \\
112 \\
46\end{array}$ & $\begin{array}{c}11 \\
12 \\
8\end{array}$ & $\begin{array}{c}1 \\
2,20 \\
3,57 \\
0,007\end{array}$ & $\begin{array}{c}- \\
0,97-5,14 \\
1,36-9,37\end{array}$ & $\begin{array}{c}1 \\
2,22 \\
3,77 \\
0,010\end{array}$ & $\begin{array}{c}- \\
0,88-5,63 \\
1,33-10,74\end{array}$ \\
\hline $\begin{array}{c}\text { Gender } \\
\text { Males } \\
\text { Females }\end{array}$ & $\begin{array}{c}16 \\
142\end{array}$ & $\begin{array}{c}2 \\
18\end{array}$ & $\begin{array}{c}1 \\
2,40\end{array}$ & $0,82-7,03$ & $\begin{array}{c}1 \\
1,76\end{array}$ & $0,57-5,42$ \\
\hline $\begin{array}{c}\text { Age classes (years) } \\
15-25 \\
26-35 \\
36-45 \\
46-55 \\
>55\end{array}$ & $\begin{array}{c}7 \\
30 \\
56 \\
62 \\
3\end{array}$ & $\begin{array}{l}1 \\
6 \\
6 \\
6 \\
1\end{array}$ & $\begin{array}{c}1 \\
1,26 \\
1,17 \\
1,30 \\
2,00\end{array}$ & $\begin{array}{c}- \\
0,24-6,59 \\
0,24-5,80 \\
0,27-6,17 \\
0,34-11,70\end{array}$ & $\begin{array}{c}1 \\
0.98 \\
0,89 \\
1,04 \\
2,58\end{array}$ & $\begin{array}{c}- \\
0,18-5,33 \\
0,17-4,64 \\
0,21-5,15 \\
0,42-15,96\end{array}$ \\
\hline
\end{tabular}

\section{Discussions and conclusions}

The investigation results are rather promising since, in spite of the analyzed sample limited number, they evidence that the methodology is able to pick up exposure differences for MAPO screening index levels. It is however noteworthy that OR regarding MAPO exposure class between 1.51 and 5 was not significant (correct IC 95\%: 0.88-5.63) whereas OR regarding exposure class over 5 was significant (correct IC 95\% 1.33-10.74).

For application, proposed screening methodology could be considered to be reliable for high exposures (MAPO screening value higher than 5) while for intermediate exposure, it has to be checked by analytical investigation.

No doubt the impossibility to use an internal reference group because of the reduced number of subjects exposed to negligible MAPO risk may pose some result interpretation problems. However it has to be recalled that as to the reference group used for other studies $(13,15)$ where prevalence of subjects with at least one episode of acute low back pain in the last year was equal to $2.3 \%$, in the reference group used, the prevalence was double and equal to $4.6 \%$. Besides, this group has special time and space characteristics as compared with exposed subjects.

It is then necessary to consider some issues regarding the special methodologies used in this study.
As regards the need to provide more stringent (more objective) criteria, it is worth underlining the following:

a) analytical observation of handling activities both in terms of patient total lifting and for partial displacements/lifting, allows to describe how many of them are carried out manually as compared with aided activities. Thus actual adequacy of available ward equipment is quite apparent even if with some inaccuracy margins: furthermore, it is important to find solutions fitting that special reality. Actually knowledge of type of patient and type of handling surely facilitates choice of appropriate solutions.

b) the possibility of including in the Op calculation (operators present over the 24 hours) the subjects more and more working with split working times and vertical and horizontal part time, is a need just dictated by changes in working time organization that have occurred in the last years and quite apparent in this study.

c) The last requirement is associated with attribution procedure of Training Factor. As compared with the proposals set forth in 1999 (32) and in 2006 (5), when however education to specific risk was practically unexisting, two further criteria shape its adequacy: number of trained operators and possible effectiveness check.

Another methodological issue deals with irrelevant attribution for wheelchair and environment factors: 
in fact in calculating screening MAPO index these factors were set equal to one.

It is noteworthy that the conclusions drawn in the present study being cross sectional should not only be confirmed by other similar studies but also by prospect studies epidemiologically more consistent and besides the comparison with the external reference group poses some comparability problems in respect of possible different socio-cultural background.

Another issue is concerned with work organization changes made apparent in this study: should the presence of operators in charge for short periods during the day (in particular horizontal part time) be confirmed, analysis of MAPO risk index versus lumbar injury will be more and more difficult since work loads should be analytically detailed by work time ranges.

In conclusion, the results obtained by applying MAPO screening method suggest its use as a tool able to quickly assess the most hazardous PMH situations, allowing to address the management specially in large companies but also at wider territorial level to priority actions or risk analytical in-depth investigation.

\section{References}

[1] Baiget B : "Mapa de riesgo de lesiones músculo-esqueléticas por movilización de pacientes en salas de hospitalización". Atti Congresso Internazionale ORP Valencia 5-7 maggio 2010. Reperibile su www.orpconference.org

[2] Baldasseroni A, Tartaglia R, Sgarrella C, Carnevale F. Frequency of lumbago in a cohort of nursing students. Med Lav 1998; 89(3): 242-53

[3] Baldasseroni A, Abrami V, et al: Longitudinal study for assessing the efficacy of preventive measures in a population of health workers exposed to the risk of patient lifting. G Ital Med Lav Ergon 2005; 27(1):101-5

[4] Battevi N, Consonni D, et al: L'applicazione dell'indice sintetico di esposizione nella movimentazione manuale pazienti: prime esperienze di validazione. Med Lav 1999; 90 (2): 256-275

[5] Battevi N, Menoni O, et al: MAPO index for risk assessment of patient handling in hospital words. Ergonomics 2006; 49 (7):671-687

[6] Berloco F. Risultati della valutazione del rischio e del danno negli operatori sanitari dei reparti di degenza: confronto tra due studi multicentrici. Atti Seminario: La movimentazione manuale dei pazienti in ospedale "Risultati e prospettive dello studio multicentrico Ospedali 2003 Milano. Reperibile su: www.epmresearch.org

[7] Beruffi M, Mossini M, et al. The assessment of exposure to the risk of the manual lifting of patients and the results of a clinical study in the rest homes of the Mantua area. Med Lav 1999; 90(2):291-307
[8] Bonatti D, Bombana S. Rischio e sorveglianza sanitaria a personale tecnico-assistenziale operante in un servizio di radiologia medica. Atti Seminario Internazionale "La gestione del rischio da movimentazione manuale di pazienti, confronto internazionale di idee per soluzioni ergonomiche" Milano 2010. Reperibile su: www.epmresearch.org

[9] Cairoli S, Vitelli N, et al. I risultati dello screening rischio/danno effettuato nelle strutture ospedaliere liguri. Atti Seminario "La gestione del rischio da movimentazione pazienti nelle strutture ospedaliere: esperienze regionali e prospettive". Genova 2009. Reperibile su: www.epmresearch.org

[10] Carta A, Parmigiani F, et al. Disabilità e lombalgia in addetti alla movimentazione manuale pazienti in una grande azienda ospedaliera. G Ital Med Lav Ergon 2007; 29:581-583

[11] Caruso CC, Waters TR. A review of work schedule issues and musculosckeletal disorders with an emphasis on the healthcare sector. Ind Health 2008; 46: 523-534.

[12] CEN EN 1005-2. Safety of machinery - Human physical performance - Part 2:Manual handling of machinery and component parts of machinery. 2003

[13] Colombini D et al. La lombalgia acuta da movimentazione manuale di pazienti nei reparti di degenza:dati di prevalenza e di incidenza. Med. Lav. 1999; 90 (2): 229-243.

[14] Colombini D, Riva D, et al. Primi dati epidemiologici di esperienze nazionali sugli effetti clinici negli operatori sanitari addetti alla movimentazione manuale di pazienti nei reparti di degenza . Med Lav 1999; 90 (2): 201-228

[15] Colombini D, Occhipinti E, et al. Linee Guida per la prevenzione dei disturbi e delle patologie muscoloscheletriche del rachide da movimentazioni manuale dei carichi. In: Apostoli P, Imbriani M, Soleo L, Abritti L (eds). PI-ME Editrice, Pavia 2004: Vol 10

[16]Consonni D. L'indice MAPO e la sua relazione col danno lombare acuto. Atti Seminario: La movimentazione manuale dei pazienti in ospedale "Risultati e prospettive dello studio multicentrico Ospedali 2003 Milano. Reperibile su: www.epmresearch.org

[17]Engkvist IL, Hjelm EW, et al. Risk indicators for reported over-exertion back injuries among female nursing personnel. Epidemiology 2000; 11(5): 519-22

[18]Folletti I, Belardinelli V, et al. Prevalence and determinants of low back pain in hospital workers. G Ital Med Lav Ergon 2005; 27(3): 359-61

[19] Hignett S. Work-related back pain in nurses. J Adv Nurs 1996; 23(6): 1238-46

[20] Hignett S., MCATAMnEy L. "REBA". Appl Ergon 2000; 31: 201-205

[21]ISO 11228-1. Ergonomics - Manual handling - Lifting and carrying -2003

[22]ISO 11228-2. Ergonomics - Manual handling - Pushing and pulling- 2007

[23]Jager M, Jordan C, et al. Spinal-load analysis of patienttransfer activities. In Buzug, Thorsten M (Ed): Advances in medical engineering. Springer, 2007: 273-278

[24] Jang R, et al: Biomechanical evaluation of nursing tasks in a hospital setting. Ergonomics 2007; 50 (11): 1835-1855

[25] Knibbe JJ, Friele RD. The use of logs to assess exposure to manual handling of patients, illustrated in an intervention study in home care nursing. International Journal of Industrial Ergonomics 1999; 24: 445-454.

[26] Larese F, Fiorito A. Musculoskeletal disorders in hospital nurses: a comparison between two hospitals. Ergonomics. 1994; 37(7):1205-11 
[27] Lorusso A, Bruno S, L'Abbate N. A review of low back pain and musculoskeletal disorders among Italian nursing personnel. Ind Health. 2007; 45(5): 637-44

[28] Marena C, Gervino D, et al. Epidemiologic study on the prevalence of low back pain in health personnel exposed to manual handling tasks. G Ital Med Lav Ergon 1997; 19(3): 89. 95.

[29] Marras W. The Working Back. J. Wiley \& Sons, Inc. Pub, 2008.

[30] Maso S, Furno M, et al. Musculoskeletal diseases among a group of geriatric residence workers. G Ital Med Lav Ergon 2003; 25 Suppl(3): 194-5

[31] Menoni O, Ricci MG, et al. Valutazione dell'esposizione ad attività di movimentazione manuale dei pazienti nei reparti di degenza: metodi, procedure, indice di esposizione (MAPO) e criteri di classificazione. Med. Lav. 1999; 90 (2): 152-172

[32] Menoni O, Battevi N, et al. Il metodo MAPO per l'analisi e la prevenzione del rischio da movimentazione pazienti. In Franco Angeli Editore; Milano 2011

[33]Ricci MG, Menoni O, et al. Studi clinici negli operatori sanitari addetti alla movimentazione manuale dei pazienti: metodi per la rilevazione delle affezioni del rachide. Med Lav 1999; 90 (2): 173-190

[34]Ricci MG. La valutazione del rischio nei blocchi operatori metodi e procedure. Atti Seminario: La movimentazione manuale dei pazienti in ospedale "Risultati e prospettive dello studio multicentrico Ospedali 2003 Milano. Reperibile su: www.epmresearch.org
[35] Rothmans K. In Modern epidemiology. Little Brown and co 1986; Boston - Toronto

[36] Stanton NA, Hedge A, Salas E, Hendrick W: Assessment Of Exposure to Manual Patient Handling in Hospital Wards: MAPO INDEX (Movement and Assistance of Hospital Patients). In Handbook of Human Factors and Ergonomics Methods; CRC pres 2004. 16.1 - 16.11

[37] Stobbe TJ, et al: Incidence o Low Back Injuries Among Nursing Personnel as a Function of Patient Lifting Frequency. Journal of Safety Research, 1988; 19: 21-28

[38] Violante FS, Fiori M, et al. Associations of psychosocial and individual factors with three different categories of back disorder among nursing staff. J Occup Health 2004; 46(2):100108.

[39] Violante FS, Bonfiglioli R, et al. Linee Guida per la prevenzione delle patologie correlate alla movimentazione manuale dei pazienti. In: Apostoli P, Imbriani M, Soleo L, Abritti L (eds). Linee guida per la formazione continua e l'accreditamento del medico del lavoro. Tipografia PI-ME Editrice, Pavia -2008: Vol. 23.

[40] Waters T, Nelson A, et al. Patient Handling Tasks with High Risk for Musculoskeletal Disorders in Critical Care. Crit Care Nurs Clin N Am 2007; 19: 131-143

[41] Yassi A, Khokhar J, et al. The epidemiology of back injuries in nurses at a large Canadian tertiary care hospital: implication for prevention. Occup Med 1995; 45(4): 215-220 